\title{
Conceptual Design of a Six DOF Hybrid Kinematic Machine for On-Site Machining
}

\author{
Maxwell Zvikomborero Sakutukwa ${ }^{1}$, Anshul Jain ${ }^{2}$ \\ ${ }^{1,2}$ Department of Mechanical Engineering, ITM University, NH-75 Jhansi road, Gwalior, MP, India
}

\begin{abstract}
On-site machining has received very little attention from the machine tool manufacturing research community. With the increasing need for on-site machining services in many sectors, kinematic machines specially designed for on-site machining are on high demand. From the second half of the $20^{\text {th }}$ century to date, Serial and Parallel Kinematic Machines have earned a great deal of attention from the machine tool manufacturing industry. The reasons being short processing time, low manufacturing costs, high rigidity, accuracy and dynamic response of these structures. However, owing to the advantages and disadvantages of both systems, designers have redirected their focus to hybrid systems which optimizes the advantages of these two structures. In this paper a six DOF Hybrid kinematic machine structure, which combines parallel and serial kinematic substructures, is developed specifically for on-site milling operations of large components. This design is dedicated to on-site milling operations which require a mobile and flexible equipment to take care of the complex nature the operations. Autodesk Inventor is used in modeling and parameter optimization of the hybrid kinematic structure. Finally the conceptual model and its basic dimensions are presented.
\end{abstract}

Keywords: Hybrid Kinematic Machine, On-site machining, Conceptual design, Structural synthesis, Optimization.

\section{Introduction}

On-site machining has become a need in an attempt by companies to increase productivity, reduce machine down time and reduce transportation costs. The only challenge is to find a suitable machine tool which can provide the required accuracy, rigidity, flexibility and high dynamic response when carrying out on-site machining activities. In the past decade kinematic machine tools were proposed [1], [2] and some were successfully employed on CNC machines in the form of serial and parallel kinematic machine tools ranging from 2 DOF to 6 DOF. However no sustainable kinematic machine tool has been designed to handle on-site machining of large components and features that are often located in places not easily accessible. Modern development trends in the field of machine tool design have pointed in the direction of hybrid kinematic machine tools as a solution to designing sustainable kinematic machine tools for complex tasks. In this paper the conceptual design of a six DOF hybrid kinematic machine is presented. The design is developed through a structural synthesis process which employs several techniques to come up with a design which satisfies the design requirements.

This paper is organized as follows: The next sections present the literature survey, followed by the structural synthesis in section 3. Section 4 discusses in detail the conceptual design of the hybrid kinematic machine. Finally component optimization and areas of future work are presented before conclusions are draw.

\section{Literature Survey}

Literature survey on the design and development of different types of kinematic machines was conducted in detail. Kinematic machines have attracted many researchers over the past three decades (Zhang et al. 2013). Much effort has been made on serial manipulators for various applications. More recently, the development of parallel robotics has begun to show its advantages. Parallel manipulators (PMs) have many advantages over serial structures. These are typically claimed as high payload to weight ratio, velocity, accuracy, stiffness, and low inertia [7]. Many variations have been proposed in the research literature of kinematic machine tool design [1], [2], [6]. Currently the most successful equipment in developed countries is a flexible manufacturing unit based on reconfigurable PKM such as Tricept, Sprint Z3 and Exechon [8]. Owing to the advantages and limitations of both serial and parallel kinematic machines, research trends have shifted towards hybrid kinematic machine tool structures. A hybrid kinematic machine tool is one which incorporates the features of both the serial and the parallel kinematic machine tool structures [5]-[7]. The TRICEPT is a hybrid KM, having two main parts, the tripod, made up of the 3 actuators and the central tube, and the serial wrist. The tripod is a purely parallel structure, whereas the spherical wrist is a purely serial structure. Combining together these two structures, combine the best characteristics of both parallel and serial kinematic machine worlds. The TRICEPT hybrid kinematic machine has high accuracy, high stiffness and speed, while its workspace is much bigger than the machines based on structures that are purely parallel. Another well-known successful hybrid kinematic machine tool is the Exechon HKM however [7] suggested another topology of this type of machine and proposed an optimal kinematic design formulation for optimizing the various parameters on the Exechon kinematic machine.

A reasonable number of researchers have proposed hybrid structures basing on the TRICEPT and the Exechon. A Reconfigurable swing link parallel kinematic structure was proposed by Coppola (2014). This mechanism enables the machine to reconfigure without human interaction. Another interesting concept is "a novel 4-DOF hybrid parallel kinematic machine (PKM), named Bicept, comprising a 2DOF parallel mechanism plus a 2-DOF rotating head" which was proposed by Huang (2010). 


\section{International Journal of Science and Research (IJSR) \\ ISSN (Online): 2319-7064}

Index Copernicus Value (2013): 6.14 | Impact Factor (2014): 5.611

\section{Structural Synthesis}

According to Merlet (2006)"Structure synthesis is the domain in which a methodology is used to try to generate all the structures that have a desired kinematic performance." Unlike serial manipulators which have limited number of structures parallel and hybrid manipulators have a variety of possible close-loop mechanisms, and the topology of the structure will affect the overall performance of the robot. For many applications, less than six DOF may be needed. For milling operation in the machine-tool domain, the rotation of the platform around its normal is not needed, as the spindle will manage this DOF hence only five DOF are needed. The universal Somo-Malushev's mobility formulae:

$$
M=I(L-j-1)+\sum_{i=1}^{j} f_{i}+s
$$

Is commonly used for structural synthesis, however this approach may have difficulties to deal with the synthesis of robots with less than 6 DOF [7], [11].The graph theory, the group theory and the screw theory are also widely used in structural synthesis by researchers. The structural synthesis of the hybrid kinematic machine was done using an integral approach which incorporates all the stated theories. The system was decomposed into subassemblies which provide the desired mobility when assembled together. A range of available joints were analyzed in order to select the best topology for the desired milling operations. A motor selection process was also conducted basing on the calculated maximum design loads that can be applied to the tool frame. The main objective of the structural synthesis process is to develop a structure which provide the desired mobility and satisfy the workspace requirements.

\section{Conceptual Design}

After clearly understanding the design requirements for onsite machining tools, several possible solutions were developed through the synthesis process. The preferred concept was further developed as a set of 3 subassemblies consisting of (1) two prismatic joints connected in series orthogonal to each other which provides two translational DOF to the entire system, (2) the three limb parallel structure which provides two DOF to the system and (3) the serial wrist which also provide two DOF to the entire system giving a total of six DOF to the hybrid kinematic machine. From the design calculations the parameters presented in tables (1-3) were obtained for the hybrid kinematic machine. Fig (1-3) shows the 3D models of the three subassemblies of the hybrid kinematic machine.

Table 1: Design parameters for the $\mathrm{x}$ and $\mathrm{z}$ tables

\begin{tabular}{|l|l|}
\hline Design Parameter & Value \\
\hline Bounding box for structure (mm) & $600 \times 450 \times 300$ \\
\hline Lead screw diameters (mm) & 20 \\
\hline Lead screw lengths (mm) & $600 \& 450$ \\
\hline Servomotor sizes & $0.5 \mathrm{~kW}$ \\
\hline
\end{tabular}

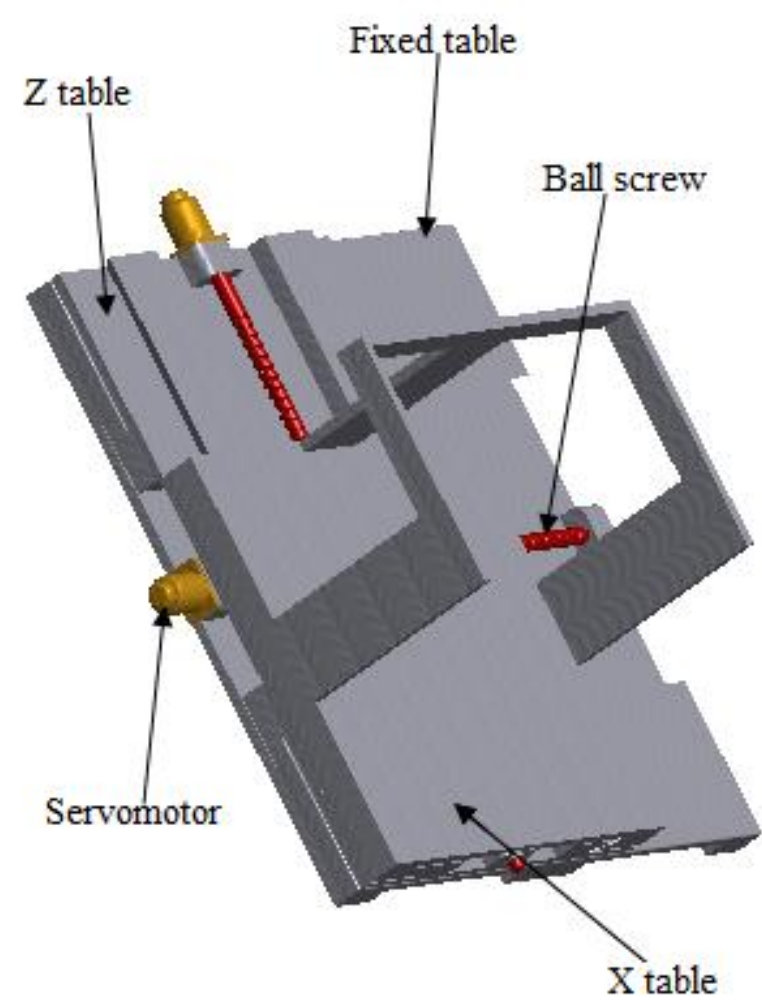

Figure 1: 3D model of the $\mathrm{x}$ and $\mathrm{z}$ translatory tables

This structure provides the 2 translatory motion for the hybrid kinematic machine in the $\mathrm{x}$ and $\mathrm{z}$ axis according to the frames assigned during the structural synthesis. The design employs 2 prismatic joints in the form of dove tails which permits motion only in orthogonal directions through ball screw assemblies.

Table 2: Design parameters for the parallel substructure

\begin{tabular}{|c|c|}
\hline Design Parameter & Value \\
\hline Mobile platform diameter (mm) & 160 \\
\hline Lead screw diameters (mm) & 16 \\
\hline Lead screw lengths (mm) & 250 \\
\hline Link lengths (mm) & 215 \\
\hline
\end{tabular}

A parallel manipulator usually consists of a mobile platform that is connected to a fixed base by at least two independent kinematic chains acting in parallel [6]. Fig 2 shows a conceptual design of a parallel structure to be integrated in the hybrid kinematic machine. "The Stewart and the Gough's platform are the best known parallel manipulator formed from six linear actuators that support a movable base for devices such as flight simulators" [10], [11]. High rigidity, speed and accuracy as well as large load carrying capacity are the desired benefits of PKM [1]-[13] 


\section{International Journal of Science and Research (IJSR) \\ ISSN (Online): 2319-7064}

Index Copernicus Value (2013): 6.14 | Impact Factor (2014): 5.611

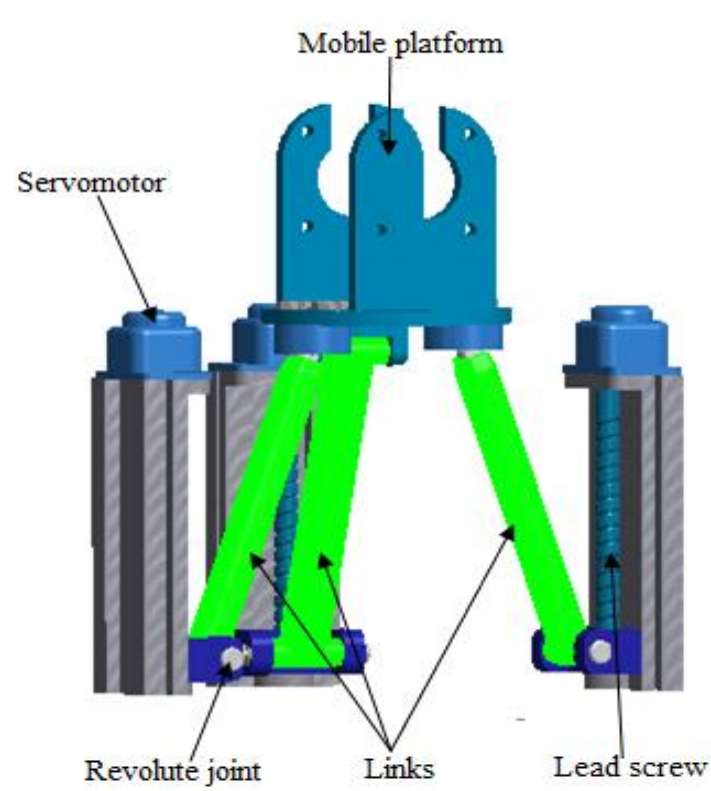

Figure 2: 3D model of the conceptual parallel structure

Fig 3 shows the 3D model of the serial wrist. This substructure's main function is to orient the tool as desired during the machining operation as well as providing the much needed cutter rotational motion. The basic parameters for the serial wrist are presented in table 3. It can be observed that this substructure is very critical as far as the rigidity of the hybrid structure is concerned hence extra care must be taken in designing its components.

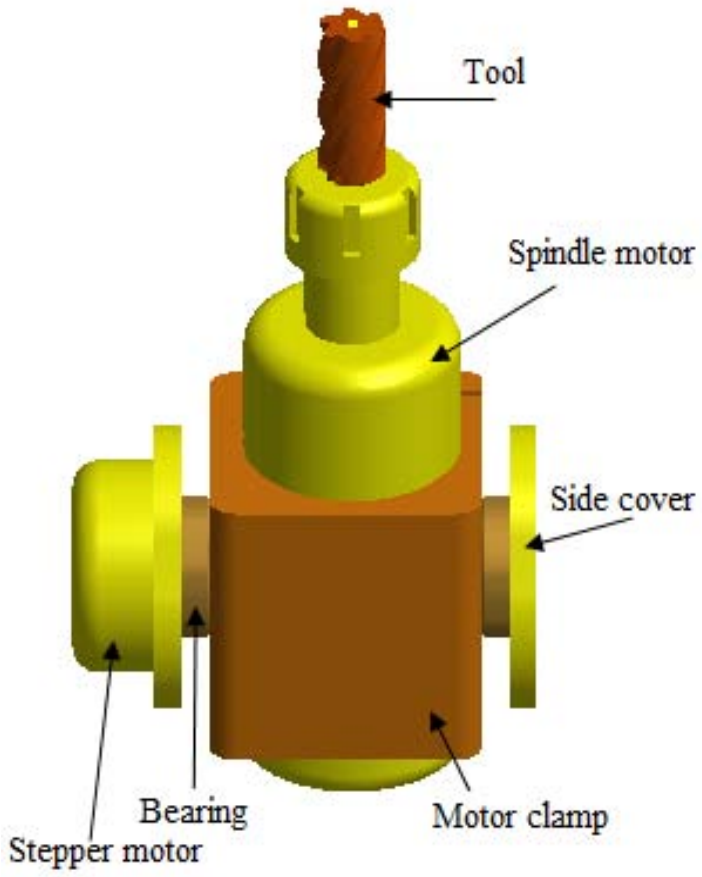

Figure 3: 3D model of the conceptual serial wrist

Table 3: Design parameters for the serial wrist

\begin{tabular}{|l|l|}
\hline Design Parameter & Value \\
\hline Tool diameter $(\mathrm{mm})$ & 30 \\
\hline Spindle motor size $(\mathrm{kW})$ & 1.54 \\
\hline Stepper motor size $(\mathrm{kW})$ & $0.4 \mathrm{~kW}$ \\
\hline Spindle motor clamp $(\mathrm{mm})$ & $100 \times 100 \times 100$ \\
\hline
\end{tabular}

\subsection{Parameter Optimization}

With all design parameters for the three sub-assemblies calculated, the components were further optimized to make sure that the resulting hybrid structure is optimum in terms of cost, strength and weight among other parameters of interest. The optimization process was conducted on a component level where each component was loaded basing on the calculated end effector forces and moments. Table 4 presents the end-effector forces and moments which were calculated from conventional design formulas.

Table 4: Maximum allowable end-effector loads

\begin{tabular}{|l|l|}
\hline Parameter & Value \\
\hline Force in $\mathrm{x}$ direction $\left(\mathrm{F}_{\mathrm{ex}}\right)$ & $525 \mathrm{~N}$ \\
\hline Force in $\mathrm{x}$ direction $\left(\mathrm{F}_{\mathrm{ev}}\right)$ & $525 \mathrm{~N}$ \\
\hline Force in $\mathrm{x}$ direction $\left(\mathrm{F}_{\mathrm{ez}}\right)$ & $500 \mathrm{~N}$ \\
\hline Torque about the tool axis & $7.86 \mathrm{Nm}$ \\
\hline
\end{tabular}

Tools are provided in Autodesk Inventor software for component optimization. Fig 4 shows the $3 \mathrm{D}$ model of the final conceptual design of the hybrid kinematic machine for on-site machining. The topology of this mechanism is a $\mathbf{2} \underline{\mathbf{P}}+\mathbf{( 2} \underline{\mathbf{P R U}} \mathbf{P} \mathbf{R R})+\mathbf{2} \underline{\mathbf{R}}$. This is a hybrid kinematic structure which is made up of 2 prismatic joints connected in series, which drive a 3 limb parallel structure and a serial wrist with 2 revolute joints is attached to the mobile platform of the parallel structure.

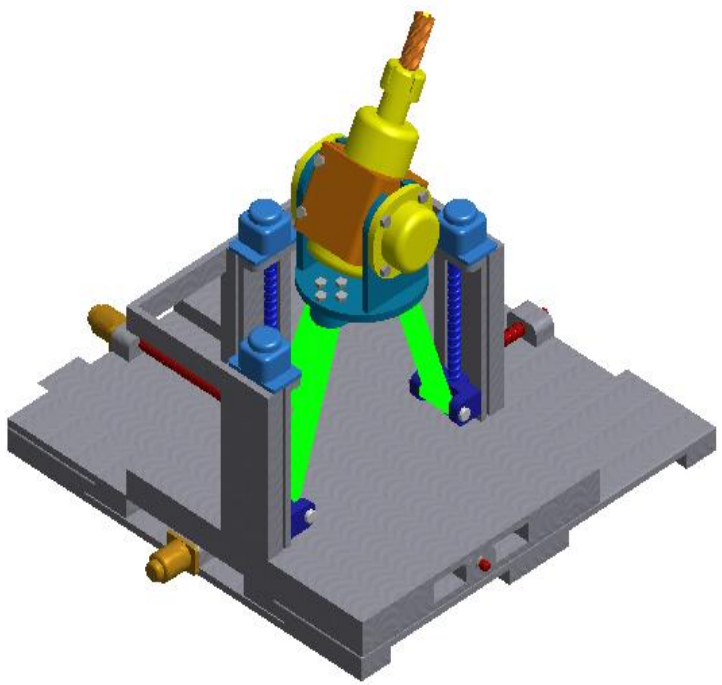

Figure 4: Hybrid kinematic machine

\subsection{Areas for Future Investigation}

1)According to Merlet (2006) structural synthesis is an exciting domain with a large number of open problems which needs more research work.

2)In machine tool design the application of constant length struts require an in-depth analysis since a preliminary analysis indicated that they have better stiffness compared to variable length struts [16].

3)More work should be done to try and convert the proposed structures into working prototypes and further implement the proposed designs as suggested in [10] and [15]. 


\section{International Journal of Science and Research (IJSR) \\ ISSN (Online): 2319-7064}

Index Copernicus Value (2013): 6.14 | Impact Factor (2014): 5.611

\section{Conclusions}

This paper presents the conceptual design of a six DOF hybrid kinematic machine tool for on-site machining. A variety of techniques were employed in the synthesis of the desired architecture including the group theory, the graph theory, the screw theory, the Denavit and Hartenberg (DH) convention and the mobility approach. The hybrid structure was achieved by designing 3 subassemblies which are integrated together to make a structure suitable for the desired on-site milling operations. A component optimization was carried out with the help of Autodesk inventor and the final model was presented. From the design approach that was used the concept proved to be suitable for the design requirements hence detailed static and dynamic analysis can be pursued to further verify and validate the feasibility of the conceptual design.

\section{References}

[1] Zhang, D., Gao, Z. (2012). "Forward kinematics, performance analysis, and multi-objective optimization of a bio-inspired parallel manipulator," Robotics and Computer-Integrated Manufacturing, 28(4), pp.484492.

[2] Gao, Z., Zhang, D. and Ge, Y. (2010). "Design optimization of a spatial six degree-of-freedom parallel manipulator based on artificial intelligence approaches," Robotics and Computer-Integrated Manufacturing, 26(2), pp.180-189.

[3] Stoughton, R. and Arai, T. (1993). "A modified Stewart platform manipulator with improved dexterity," IEEE Trans. Robot. Automat. 9(2), pp.166-173.

[4] Huang, T., Wang, J., Gosselin, C. and Whitehouse, D. (2000). "Kinematic Synthesis of Hexapods with Specified Orientation Capability and Well-Conditioned Dexterity," Journal of Manufacturing Processes, 2(1), pp.36-47.

[5] Coppola, G., Zhang, D., Liu, K., (2014). “A 6- DOF reconfigurable hybrid parallel manipulator," Robotics and computer- integrated manufacturing, (30), pp. 99106

[6] Zhang, D., Su, X., Gao, Z. and Qian, J. (2012). “Design, analysis and fabrication of a novel three degrees of freedom parallel robotic manipulator with decoupled motions," International Journal of Mechanics and Materials in Design, 9(3), pp.199-212.

[7] Harib, K., Ullah, A. and Moustafa, K. (2013). “Optimal Design for Improved Hybrid Kinematic Machine Tools Structures," Procedia CIRP, 12, pp.109-114.

[8] Li, Y., Zhang, E., Song, Y. and Feng, Z. (2013). "Stiffness modeling and analysis of a novel 4-DOF PKM for manufacturing large components," Chinese Journal of Aeronautics, 26(6), pp.1577-1585.

[9] Joshi. S, Tsai. L.W. (2002). "Jacobian Analysis of Limited-DOF Parallel Manipulators," Mechanical Design Trans ASME, 124(2), pp. 254-258.

[10] Merlet. J.P. (2006). Parallel Robots, 2nd edition. Springer, Dordrecht

[11] Firmani, F. and Podhorodeski, R. (2009). "Singularity analysis of planar parallel manipulators based on forward kinematic solutions," Mechanism and Machine Theory, 44(7), pp.1386-1399.

[12] Zlatanov. D, Bonev. I, Gosselin. C.M. (2002). "Constraint singularities of parallel mechanism," In: Proceedings on IEEE International Conference of Robotics and Automation, Washington DC.

[13] Gosselin, C.M., Zhang, D. (2002). "Stiffness analysis of parallel mechanisms using a lumped model" International Journal of Robotics and Automation, 17, pp.17-27.

[14] Saha. S.K. (2008). Introduction to robotic, Tata McGraw-Hill Publishing Company Limited, New Delhi,

[15] Craig. J. (2005). Introduction to Robotics Mechanics and Control, Third Edition. Pearson Prentice Hall.

[16] Tlusty, J., Ziegert, J. and Ridgeway, S. (1999). "Fundamental Comparison of the Use of Serial and Parallel Kinematics for Machines Tools," CIRP Annals - Manufacturing Technology, 48(1), pp.351-356.

\section{Author Profile}

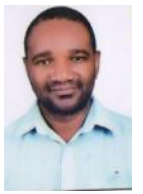

Maxwell Zvikomborero Sakutukwa is a Post Graduate student pursuing M.Tech degree in Machine Design at (Institute of Technology and Management) I.T.M University, Gwalior, M.P, India., he is a holder of a B.Tech Honors Degree in Industrial and Manufacturing Engineering from Harare Institute of Technology, Zimbabwe which was awarded in 2012. Before university education he was trained as an apprentice Fitter and Turner by National Railways of Zimbabwe. His research interests include Computer Aided Design, Robotics and Automation.

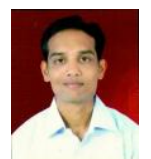

Anshul Jain is currently working as an Assistant Professor at ITM University, Gwalior. He has done his M.Tech from NIT Allahabad in CAD/CAM. He has more than three years of teaching experience. Some of his work has been presented in national and international conferences. His research interests include CAD/CAM, Robotics and Rapid Prototyping. 